\title{
Power Quality Improvement of Distribution Network Using Optimum Combination of Battery Energy Storage System and Capacitor Banks
}

\author{
A. Lallu, F. R. Islam, K. A. Mamun, K. Prakash and M. Cirrincione \\ School of Engineering \& Physics (SEP) \\ University of the South Pacific \\ Suva, Fiji \\ avneellallu@hotmail.com
}

\begin{abstract}
This paper proposes static and dynamic Volt Amp Reactive (VAR) planning based on the active and reactive power profile enhancing for dynamic voltage stability of distribution networks with Battery Energy Storage System (BESS) and capacitor bank using VAR planning scheme on distribution networks. Firstly, the impact of dynamic high impedance and resistive non-linear loads in the static voltage stability of the system has been studied and the effects of complex load behaviour on system dynamical performance is presented through a system stability analysis for three network structures. A VAR planning method is proposed where active and reactive loadability $(P-Q)$ is considered to analyse the vulnerability of the network to voltage collapse and system inefficiency. Compensating devices are placed considering P-Q loadability to improve system voltage profile and stability limit. Finally, a cost-effective combination of BESS and capacitor bank is determined through static and dynamic analysis to ensure voltage stability of the network. The results show that the proposed approach can reduce the required sizes of compensating devices which reduces costs, enhances the voltage regulation of the system and minimizes power losses.
\end{abstract}

Keywords-Battery Energy Storage System, Capaciptor Bank, Optimization, VAR Planning, Distirbution Network, Power Losses

\section{INTRODUCTION}

Electrical utility companies across the world are facing huge societal and political pressure to design more efficient electrical grids by implementing strategies to reduce energy losses. Efficiency can be improved if the amount of reactive power along transmission and distribution lines to the loads could be reduced. In others words, the higher the reactive power demand, the less efficient the grids become for the utilities.

Generation, transmission and distribution of the power is a complex process which requires a large amount of equipment and components to produce and deliver the maximum power demand. For instance, non-linear loads required reactive power therefore, it is essential to manage reactive power in an efficient way to reduce power loss. This can be done through reactive power compensator [1-3]. Reactive power compensation can improve the voltage regulation and system performance with large fluctuation of load [4].

In recent years, static VAR compensators such as Static Synchronous Compensator (STATCOM), Battery Energy Storage System (BESS) and Series/Shunt Capacitor have been used to improve the power quality of the grid. The performances of these compensators are quite satisfactory in absorbing or generating real and reactive power to support the system. The use of these devices increases the apparent power transferred through the transmission lines resulting in more stability in the network by adjusting voltage level, phase angles, current, frequency and power factors.

By placing suitable compensators at the reactive load center distribution systems reactive load demand from the main source can be reduced [5]. The lagging current reactive load can be effectively cancelled by the leading current reactive load which can be provided by the capacitors. If the compensator is placed either too far or too ahead beyond the system's inductive loads area, the compensators will still be able to provide reactive loading relief although not at their fullest [6]. This paper will highlight and propose a VAR planning technique and explain how BESS and optimal capacitor placement (OCP) will reduce real and reactive power losses in various distribution networks (radial, ring and mesh) with an effective economic analysis.

\section{TEST DISTRIBUTION NETWORK}

In this research IEEE 13-bus distribution radial feeder has been consider as the test distribution network [7]-[9] by converting all lines in to three phase. Later the network has been modified to ring network and mesh network to demonstrate how the proposed combination can compensate the reactive power, enhance voltages and minimize losses. Details about the different type of network structure are found in [10-13]. The single line diagram of Fig. 1, has been simulated in Electrical Power System Analysis Software (ETAP) under various network configurations using the switching Table 1.

TABLE I

NETWORK SWITCHES

\begin{tabular}{lccccccccccc}
\hline \hline \multirow{2}{*}{ Network } & \multicolumn{10}{c}{ Switch No. } \\
\cline { 2 - 10 } & s1 & s2 & s3 & s4 & s5 & s6 & s7 & s8 & s9 & s10 & s11 \\
\hline Radial & $\circ$ & $\circ$ & $\circ$ & $\circ$ & $\circ$ & $\circ$ & $\circ$ & $\circ$ & $\bullet$ & $\bullet$ & $\bullet$ \\
Ring & $\bullet$ & $\bullet$ & $\circ$ & $\circ$ & $\circ$ & $\circ$ & $\bullet$ & $\bullet$ & $\bullet$ & $\circ$ & $\circ$ \\
Mesh & $\bullet$ & $\bullet$ & $\bullet$ & $\bullet$ & $\bullet$ & $\bullet$ & $\bullet$ & $\bullet$ & $\bullet$ & $\circ$ & $\circ$ \\
\hline \hline
\end{tabular}

- = Closed Switch; o = Open Switch 


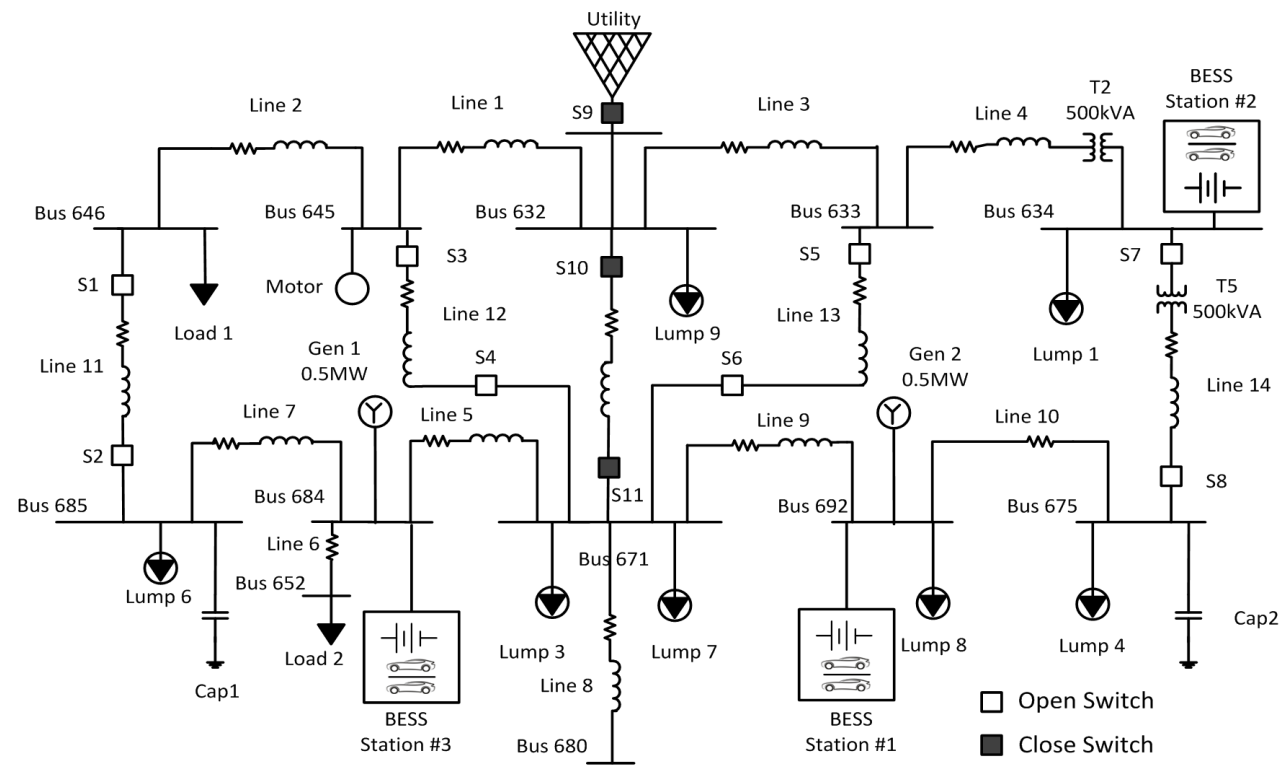

Figure 1: Single Line Diagram Test System

This network has the following characteristics [14]:

- Maximum voltage of $4.16 \mathrm{kV}$

- Three single phase wye connection units connected to a single substation voltage regulator

- Consists overhead and underground lines

- Includes shunt capacitor bank

- In-line transformer

- Distributed loads

\section{BATTERY AND CAPACITOR BANK BASED POWER FACTOR (PF) CORRECTION}

In a power distribution system, PF usually declines with the increasing reactive load which causes the voltage fluctuation, increase in system losses and reduces the system capacity. Apart from this, customers are also penalized for the higher usage of reactive power [9], [15].

The ratio between real power and apparent power is defined as power factor. To improve the system power factor, capacitors bank and battery storage system can be used. They can also improve the voltage level. A capacitor's leading current causes a voltage rise in the branches of the system.

The current in branch $(i, k)$ connecting buses $i$ and $k$ is given by equation (1) [16]:

$$
I_{i k}=\frac{P_{i k}-j Q_{i k}}{V_{i}}
$$

where

$$
\begin{aligned}
& I_{i k}=\text { Branch current }(i, k) \\
& P_{i k}=\text { Real power flow }(i, k) \\
& Q_{i k}=\text { Reactive power flow }(i, k) \\
& V_{i}=\text { Voltage at node point } i
\end{aligned}
$$

The Total Power Loss (TPL) in the transmission lines is given by equation (2) [16]:

$$
T P L=\sum_{i k=1}^{n}\left|I_{i k}\right|^{2} R_{i k}
$$

where

$$
\begin{aligned}
& n=\text { Branch current }(i, k) \\
& R_{i k}=\text { Branch resistance }(i, k)
\end{aligned}
$$

A current branch has two power components: active current $\left(I^{a}\right)$ and reactive current $\left(I^{r}\right)$. With these two components, the total loss associated with the active and reactive power components is given in [16] by equation (3) and equation (4):

$$
T P L_{a}=\sum_{i k=1}^{n}\left|I_{i k}^{a}\right|^{2} R_{i k}
$$

and

$$
T P L_{r}=\sum_{i k=1}^{n}\left|I_{i k}^{r}\right|^{2} R_{i k}
$$

In the branch, the loss $T P L_{a}$ is associated with the active components of branch current and cannot be minimized for an single source network as all active power must to be supplied by 
the source from the slack bus. Nevertheless, if the supplying part of the reactive power demand is from nearby bus, the loss $T P L_{r}$ associated with the reactive components of branch currents can be minimized.

When a capacitor draws a reactive current $I_{c}$, it only changes the reactive component of the nearby branches. This load flow solution of the reactive current of the branch has maximum loss saving at the given connection point of the branch of the nearest bus node voltage $V_{m}[16]$. The capacitor can be sized using equation (5):

$$
Q_{c}=V_{m} I_{c}
$$

where

$$
\begin{aligned}
& Q_{c}=\text { Capacitor size (kVAR) } \\
& V_{m}=\text { Voltage magnitude of bus ' } \mathrm{m} \text { ' in V } \\
& I_{c}=\text { Capacitor reactive current (A) }
\end{aligned}
$$

Based on a given set of battery characteristic curves available in the ETAP library, the required battery size in Wh and amps with depth of discharge of $80 \%$ can determined using equations (6)-(7):

$$
\begin{gathered}
\text { Total Energy } \\
\text { Required }(\mathrm{Wh}) \\
=\frac{\text { Total Load }(\mathrm{W}) \text { x Hrs of usage }(\mathrm{Hr}) \times \text { Days }}{7 \text { days }} \\
\text { Battery }(\mathrm{Ah})=\frac{\text { Total Average Watt }- \text { hour }(\mathrm{Wh})}{\text { system voltage }(\mathrm{V})} / 0.8
\end{gathered}
$$

Through the supply of real power using energy storage and addition of capacitors for reactive power, the losses in a facility can be reduced. Similar works are clearly investigated in [17] and is expressed by equation (8):

$$
\text { Loss Reduction }(\%)=\left(\frac{P_{0}-P_{n+1}}{P_{0}}\right) x 100
$$

where

$$
\begin{aligned}
& P_{o}=\text { first amount of active/reactive power loss } \\
& P_{n+1}=n^{\text {th }} \text { value of the active/reactive power loss }
\end{aligned}
$$

The charging and discharging of the BESS is required to be equal or fairly a bit more for a given day in order to ensure sustainable operation of the BESS to power the loads.

\section{OPTIMUM BESS AND CAPACITOR PLACEMENT}

The BESS charging stations were installed on the 3 weakest buses of the network for low penetration level around the distribution networks. Each of the three BESS station had the capacity to supply $1 \%$ of the total network real power (W).

The battery capacity had to satisfy the minimum and maximum voltage requirement as follow;
1. The charging voltage applied to the battery should not be more than maximum system voltage

2. The discharging battery voltage should not be less than minimum system voltage

The permanent installation of capacitors should be $1 / 2$ to $2 / 3$ of the total length of the line from the substation as a "Rule of Thumb" to obtain maximum benefit of performance improvement and reduction of losses because few uniformly distributed loads if the network is made of well-planned rural and urban circuits.

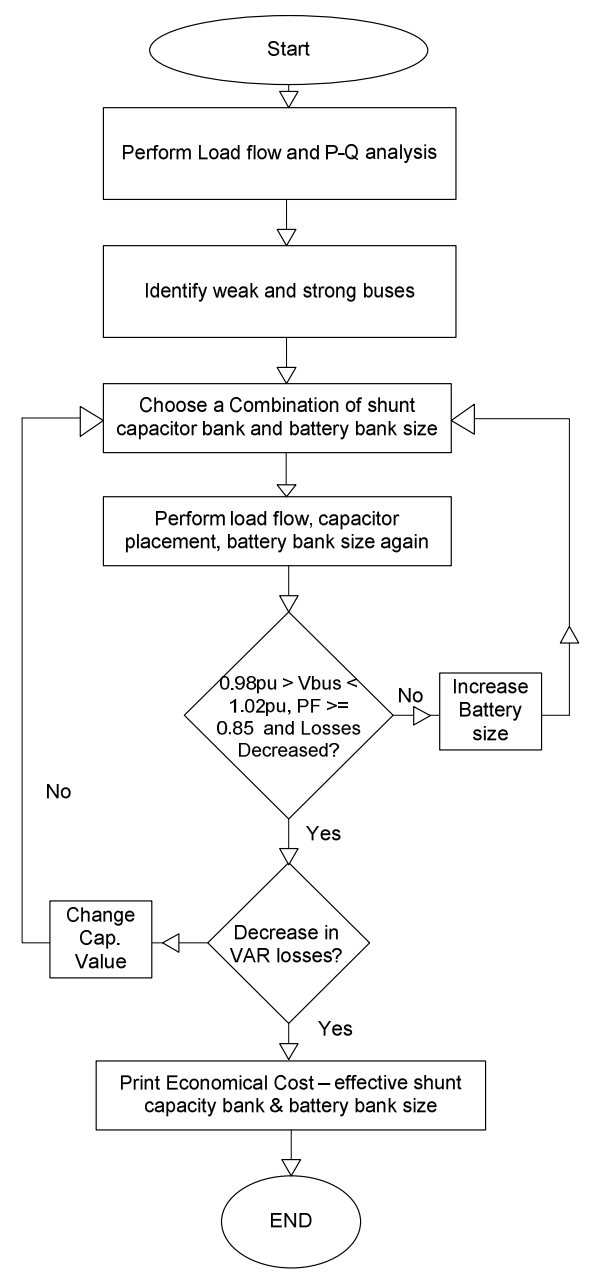

Figure 2: VAR planning scheme for optimal placement of compensators.

The constraints for capacitor placement are explained using the flowchart in Fig. 2: The constraints are as follows;

3. The power factor $(\mathrm{PF})$ should be greater than a limit of efficiency of the network 
4. All voltage magnitudes of load (PQ) buses are within the lower and upper limits

5. It meet the minimum power factor bar

The following three areas are taken in consideration for BESS and capacitors banks installation in power system:

- $\quad$ Bank size in $\mathrm{kWH}$ and $\mathrm{kVAR}$

- Location for connection

- Connection type of the transformer (Y or $\Delta$ )

The objective of optimal battery storage and capacitor banks is to minimize the cost of the operating the system using this five parts for 10 years period:

1. EV Li-Ion Battery Energy Cost $/ \mathrm{kWh}: \$ 150 / \mathrm{kWh}$

2. Capacitor installation cost: $\$ 3,000$

3. Capacitor purchase cost: $\$ 350 / \mathrm{kvar}$

4. Capacitor bank operating cost (maintenance and depreciation): \$300/Bank yr

5. Cost of real power losses: $\$ 0.16 / \mathrm{kWh}$

The flowchart highlights the 2 types of constraints which were considered for the lower and upper percentage limits in the following area for quality network performance;

- Voltage Range: 98\%-102\% (Expected $\sim 100 \%$ )

- Power Factor Range: $>0.83$ lagging (Expected 0.85 lagging)

\section{Simulation}

ETAP is a powerful fully graphical power system analysis program tool which has been used with different genetic algorithms techniques for BESS and capacitor placement in the networks. The distribution network for the 13 bus network load data can be found in the Table II of the paper which identifies the 3 weakest buses in the network and other load data on each bus.

TABLE II

13 BUS NETWORKS LOAD DATA

\begin{tabular}{ccccc}
\hline \hline Bus No. & Bus ID & kW (AC) & kVAR & Bus PF \\
\hline 1 & - & - & - & - \\
2 & 632 & 100 & 50 & 87 \\
3 & 645 & 183 & 79 & 92 \\
4 & 646 & 230 & 132 & 87 \\
5 & 633 & - & - & - \\
6 & $634^{*}$ & 400 & 290 & 81 \\
7 & 671 & 1254 & 317 & 97 \\
8 & 684 & - & - & - \\
9 & $652^{*}$ & 128 & 86 & 83 \\
10 & 685 & 170 & 80 & 90 \\
11 & 680 & - & - & - \\
12 & $692 *$ & 170 & 151 & 75 \\
13 & 675 & 843 & 462 & 88 \\
\hline
\end{tabular}

\begin{tabular}{crc}
\hline Total & 3478 & 1647 \\
\hline \hline * Identified Weak Buses &
\end{tabular}

Identified Weak Buses

From Table II, buses 692, 634 and 652 power factors are not reliable and in unstable limits which needs to be improved using installation of battery and shunt capacitors. Commercially available battery and capacitor sizes in ETAP with costs/kWh and costs/kVAR are used in the analysis.

Considering $1 \%$ of the total $\mathrm{kW}$ i.e. $3,478 \mathrm{~kW}$ of real power demand, a continuous capacity of $34.78 \mathrm{kWh}$ (per hour) battery stored of energy is required. The Li-ion batteries [18] used in this application are EV batteries which has cost an average of USD $\$ 150 / \mathrm{kwh}$ of battery energy [19] to power the loads. Table III shows the amount of battery $\mathrm{kWh}$ is required to provide 24 hours of supply for 4 cases analysis from $0 \%-3 \%$ of energy storage penetration capacity levels into the grid.

TABLE III

BAtTery Storage ENergy LEVEL For DifFERENT PENETRATION

\begin{tabular}{cc}
\hline Storage Capacity (\%) & $\mathrm{kWh} /$ day \\
\hline $0 \%$ & - \\
$1 \%$ & 834.72 \\
$2 \%$ & 1669.44 \\
$3 \%$ & 2504.16 \\
\hline
\end{tabular}

TABLE IV

LOSSES AFTER BATTERY AND CAPACITOR PLACEMENT FOR RADIAL, RING AND MESH NETWORKS

\begin{tabular}{|c|c|c|c|c|c|}
\hline \multicolumn{6}{|c|}{ Battery and Capacitor } \\
\hline Losses & Bat $\%$ & Radial & Ring & Mesh & Cap. \% \\
\hline \multirow{12}{*}{ 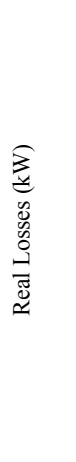 } & \multirow{3}{*}{0} & 159.6 & 262.6 & 136.3 & 0 \\
\hline & & 114.2 & 174.4 & 99.8 & 50 \\
\hline & & 112.5 & 191.6 & 97.8 & 100 \\
\hline & \multirow{3}{*}{1} & 43 & 37.6 & 44.6 & 0 \\
\hline & & 36.6 & 32.5 & 39.4 & 50 \\
\hline & & 37.5 & 38.8 & 42.1 & 100 \\
\hline & \multirow{3}{*}{2} & 37.7 & 34.6 & 37.9 & 0 \\
\hline & & 35.1 & 31.7 & 35.4 & 50 \\
\hline & & 36.4 & 34.5 & 36.2 & 100 \\
\hline & \multirow{3}{*}{3} & 34.2 & 31.2 & 36.7 & 0 \\
\hline & & 33 & 30.2 & 35.6 & 50 \\
\hline & & 34.1 & 31.6 & 36.8 & 100 \\
\hline \multirow{11}{*}{ 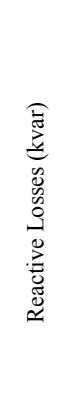 } & \multirow{3}{*}{0} & 470.7 & 705.6 & 404.9 & 0 \\
\hline & & 337.1 & 468.8 & 297.1 & 50 \\
\hline & & 332.8 & 517.3 & 289.3 & 100 \\
\hline & \multirow{3}{*}{1} & 117.7 & 100.1 & 124 & 0 \\
\hline & & 99.4 & 84.6 & 108.8 & 50 \\
\hline & & 100.7 & 98.4 & 113.4 & 100 \\
\hline & \multirow{3}{*}{2} & 103 & 91.3 & 104.9 & 0 \\
\hline & & 93.2 & 81.1 & 96.2 & 50 \\
\hline & & 93.8 & 86.4 & 96.7 & 100 \\
\hline & \multirow{2}{*}{3} & 89.7 & 75.7 & 96.6 & 0 \\
\hline & & 83.8 & 70.6 & 91.5 & 50 \\
\hline
\end{tabular}


Table IV shows comparison use of battery and capacitor with respect to reducing losses in each of the different networks. It was evident that the network had achieved stability has it had no voltage violation and suitable power factor. In Fig. 3 -Fig. 5, it illustrates the network reduction in the losses for all three networks using battery storage only for penetration of $0 \%, 1 \%$, $2 \%$ and $3 \%$ of $\mathrm{kWh}$ of battery energy storage.

The networks are then tested with capacitor bank installation with $0 \%, 50 \%$ and $100 \%$ bank of the required $\mathrm{kVAR}$ of each network buses as outlined in Table IV for the three networks to determine the most effective combination of $\mathrm{kWh}$ and $\mathrm{kVAR}$ to improve the system voltage and reduce the losses to meet the constrains.

TABLE V

COMPARISON OF PERCENTAge LOSSES IN THE NETWORK

\begin{tabular}{|c|c|c|c|c|c|}
\hline \multicolumn{6}{|c|}{ Losses Reduction in Percentage } \\
\hline & Bat $\%$ & Radial & Ring & Mesh & Cap. $\%$ \\
\hline \multirow{12}{*}{ 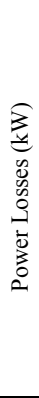 } & \multirow{3}{*}{0} & $0 \%$ & $0 \%$ & $0 \%$ & 0 \\
\hline & & $28 \%$ & $34 \%$ & $27 \%$ & 50 \\
\hline & & $30 \%$ & $27 \%$ & $28 \%$ & 100 \\
\hline & \multirow{3}{*}{1} & $73 \%$ & $86 \%$ & $67 \%$ & 0 \\
\hline & & $77 \%$ & $88 \%$ & $71 \%$ & 50 \\
\hline & & $77 \%$ & $85 \%$ & $69 \%$ & 100 \\
\hline & \multirow{3}{*}{2} & $76 \%$ & $87 \%$ & $72 \%$ & 0 \\
\hline & & $78 \%$ & $88 \%$ & $74 \%$ & 50 \\
\hline & & $77 \%$ & $87 \%$ & $73 \%$ & 100 \\
\hline & \multirow{3}{*}{3} & $79 \%$ & $88 \%$ & $73 \%$ & 0 \\
\hline & & $79 \%$ & $88 \%$ & $74 \%$ & 50 \\
\hline & & $79 \%$ & $88 \%$ & $73 \%$ & 100 \\
\hline \multirow{12}{*}{ 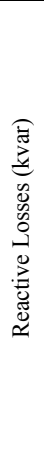 } & \multirow{3}{*}{0} & $0 \%$ & $0 \%$ & $0 \%$ & 0 \\
\hline & & $28 \%$ & $34 \%$ & $27 \%$ & 50 \\
\hline & & $29 \%$ & $27 \%$ & $29 \%$ & 100 \\
\hline & \multirow{3}{*}{1} & $75 \%$ & $86 \%$ & $69 \%$ & 0 \\
\hline & & $79 \%$ & $88 \%$ & $73 \%$ & 50 \\
\hline & & $79 \%$ & $86 \%$ & $72 \%$ & 100 \\
\hline & \multirow{3}{*}{2} & $78 \%$ & $87 \%$ & $74 \%$ & 0 \\
\hline & & $80 \%$ & $89 \%$ & $76 \%$ & 50 \\
\hline & & $80 \%$ & $88 \%$ & $76 \%$ & 100 \\
\hline & \multirow{3}{*}{3} & $81 \%$ & $89 \%$ & $76 \%$ & 0 \\
\hline & & $82 \%$ & $90 \%$ & $77 \%$ & 50 \\
\hline & & $82 \%$ & $90 \%$ & $77 \%$ & 100 \\
\hline
\end{tabular}

Using equation 8 , Table $\mathrm{V}$ shows the most significant impact of battery penetration was on Ring network of around $\sim 86 \%$ in losses reduction in real and reactive power with $1 \%$ battery penetration only. However, the mesh network had the least impact of reducing around $\sim 67 \%$ of losses for $1 \%$ of battery storage support only. With further increase of the battery penetration, the slope becomes flat indicating optimum performance based on the compensators installed was reached.
Losses for Battery for Radial Network

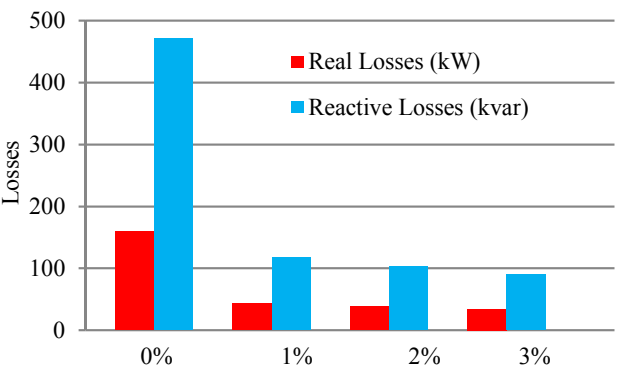

Figure 3: Losses using Battery for Radial Network ( $0 \%$ Capacitor)

Losses for Battery for Ring Network

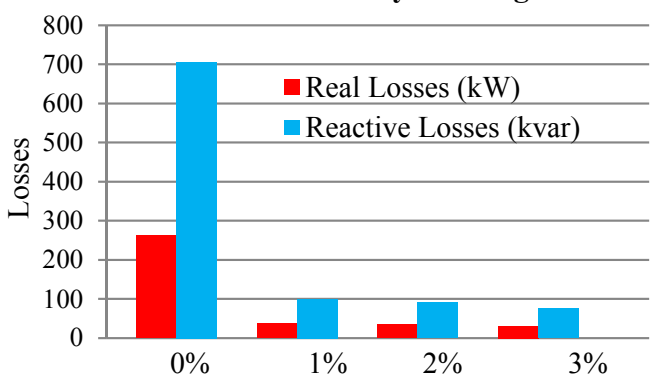

Figure 4: Losses using Battery for Ring Network ( $0 \%$ Capacitor)

Losses for Battery for Mesh Network

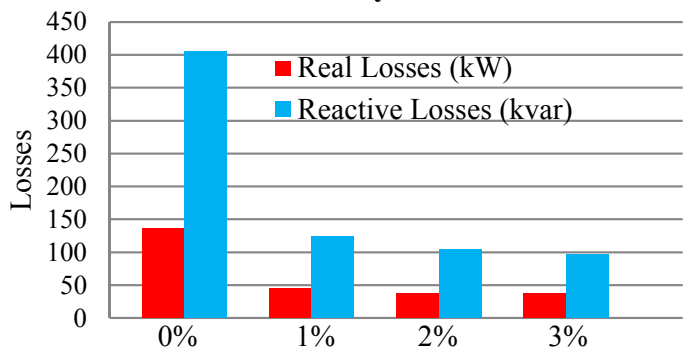

Figure 5: Losses using Battery for Mesh Network ( $0 \%$ Capacitor)

Fig. 6 -Fig. 8 illustrates the network reduction in the losses for all three networks using $3 \%$ of battery storage and capacitor for penetration of $0 \%, 50 \%$ and $100 \%$ of $\mathrm{kVAR}$. 
TABLE VI

COMPARISON BEFORE AND AFTER BATTERY AND CAPACITOR FOR RADIAL, RING AND MESH NETWORKS

\begin{tabular}{|c|c|c|c|c|c|c|c|c|c|}
\hline \multirow{2}{*}{ Constraints } & \multicolumn{3}{|c|}{ Before Battery \& Cap Placement } & \multicolumn{3}{|c|}{ After Battery $3 \%$ and Cap. $50 \%$} & \multicolumn{3}{|c|}{ After Battery $3 \%$ and Cap. $100 \%$} \\
\hline & Radial & Ring & Mesh & Radial & Ring & Mesh & Radial & Ring & Mesh \\
\hline Min Voltage (\%) & 91.25 & 86.86 & 93.51 & 99.6 & 99.42 & 99.76 & 99.79 & 99.58 & 99.96 \\
\hline Max Voltage (\%) & 98.36 & 98.09 & 98.44 & 101.15 & 101.52 & 101.01 & 101.39 & 101.73 & 101.15 \\
\hline Battery + Cap. Cost $(\$ /$ year $)$ & - & - & - & 513,312 & $1,004,624$ & 495,499 & 650,999 & $1,633,624$ & 615,374 \\
\hline Operation Cost (\$/year) & - & - & - & 568,835 & 321,365 & 491,481 & 568,835 & 321,365 & 491,481 \\
\hline Benefit (\$/year) & - & - & - & 596,366 & $1,657,150$ & 434,348 & 90,536 & $1,028,150$ & 314,473 \\
\hline
\end{tabular}

Losses for Battery Storage and Capacitor for Radial Network for 3\% Battery Penetration

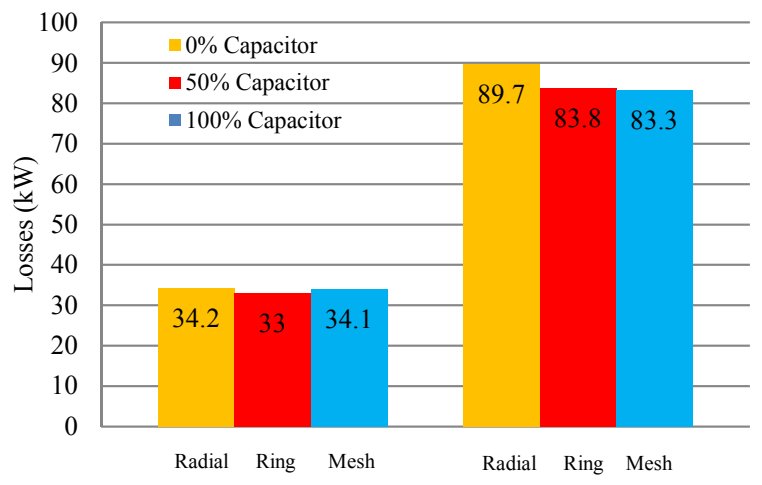

Figure 6: Losses for Battery Storage and Capacitor for Radial Network

\section{Losses for Battery Storage and Capacitor for Ring Network for 3\% Battery Penetration}

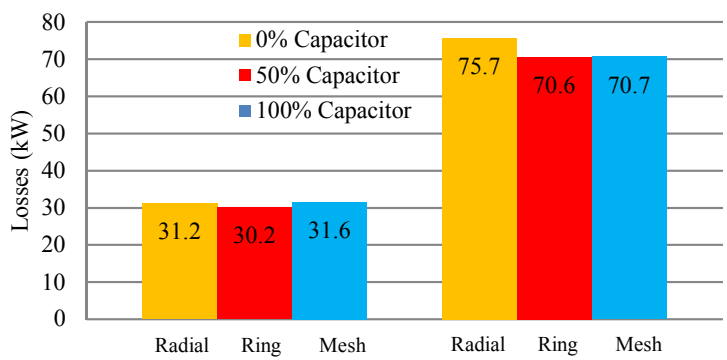

Figure 7: Losses for Battery Storage and Capacitor for Ring Network
Losses for Battery Storage and Capacitor for Mesh Network for 3\% Battery Penetration

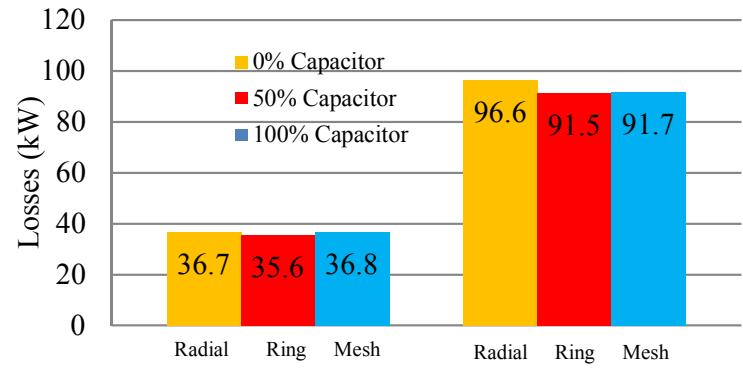

Figure 8: Losses for Battery Storage and Capacitor for Mesh Network

The three networks real and reactive losses reduced significantly for $3 \%$ penetration using 3 combinations of capacitor bank sizes.

From Table V, it can be analyzed that the 3\% battery and $50 \%$ capacitor banks installation has a significant impact in reducing network losses especially with ring network structure networks which has $\sim 88 \%-89 \%$ of reduction in real and reactive losses. Further increase to $100 \%$ capacitor banks will not be a cost effective solution to compensate power in the network based on return benefit for a 10 year plan. Hence, the best combination of battery storage and suitable value capacitor is determined based on the economic analysis with higher benefits and quick return of investment for the combination of battery and capacitor bank.

In Table VI, it shows the improvements in the system voltages and the benefits (\$/year) for 50\% capacitor and 100\% capacitor bank installation with 3\% battery penetration. The proposed VAR planning scheme shows that a combination of $50 \%$ capacitor and $3 \%$ of battery will generate less loss and more benefits in terms of revenue based on the 10 years reliability of the system. The economic benefit is illustrated in Fig. 9 which shows the saving trend of slope grow rapidly for ring network as more efficient and resilient network for compensation to improve the system static and dynamic performances. Ring networks will have an economical benefit/payback period of around 3 year using $50 \%$ of the required capacitor demand for the buses while radial and mesh network will have close to 2 years to clear up the payback but will come out with less profit than ring network in the 10 years period of investment. 


\section{Accumulative Profit}

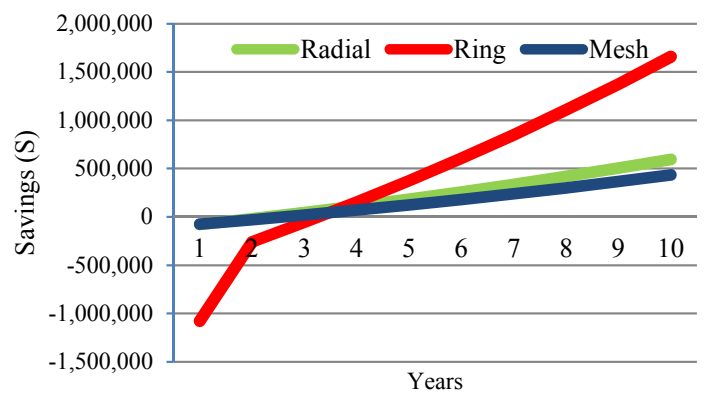

Figure 9: Economical Benefit for the three networks using $3 \%$ battery and $50 \%$ capacitor

\section{CONCLUSION}

The study of the optimum placement using the combination of BESS and capacitor banks on distribution systems for power quality improvement is presented. The proposed VAR method is studied with on a 13 bus networks structure for radial, ring and mesh network configuration to show how the proposed method minimize power losses, better operating conditions, annual benefits and improved system reliability in the presence of linear and nonlinear loads.

From dynamic analysis, radial and ring system configurations have the lowest power loss and best operating performance compared to mesh network with the combination of BESS and capacitor banks. Ring system network offers the best annual benefits using 50\% capacitor placement and 3\% BESS combination. Using this proposed combination, capacitors and battery banks can be used effectively for reactive power compensation that will improve the power factor, minimize system losses, enhancing voltage profile and increasing the feeder capacity. The following conclusion can be made from the above study analysis:

1. Optimal value of the battery bank will reduce loading of the overhead lines for active power and capacitor banks will add reactive power to the lines.

2. The algorithm flowchart finds out the estimated size and placement of the BESS and capacitor.

3. There is improvement in $\mathrm{PF}$ and voltage which helps to increase the feeder capacity.

4. Installing the battery bank improves poor power factor, huge active power demand and capacitors when it is place near the inductive reactance loads.

5. Planting capacitors near demand load centers can be limited.

\section{REFERENCES}

[1] Fink, L.H. ed., 1989. Proceedings, bulk power system voltage phenomena: voltage stability and security: Potosi, Missouri, September 19-24, 1988. Electric Power Research Institute.

[2] Fink, L.H. ed., 1994. Proceedings, Bulk Power System Voltage Phenomena III: Voltage Stability, Security, and Control: an International Seminar, Davos, Switzerland, 22-26 August, 1994. ECC.

[3] Fink, L. H., and C. D. Vournas. "Bulk power systems dynamics and control IV-restructuring." In Symposium Proceedings, Santorini, Greece. 1998.

[4] Dixon, Juan, Luis Moran, Jose Rodriguez, and Ricardo Domke. "Reactive power compensation technologies: State-of-the-art review." Proceedings of the IEEE 93, no. 12 (2005): 2144-2164.

[5] D. M. Tagare, Reactive power management, Mc-Graw Hill, 2000.

[6] Rani, Vijaya, "Distribution system loss reduction by capacitors", Proc.of National Conference on Emerging Trends in Engineering (2000).

[7] M. E. Balci, A. E. Emanuel, "Apparent power definitions: a comparison study", Int. Review Elec. Engineering, vol. 6, no. 6, pp. 2713-2722, Nov.2011.

[8] M. E. Balci, M. H. Hocaoglu, "Effects of source voltage harmonics on power factor compensation in ac chopper circuits", Electrical Power Quality and Utilisation Journal, vol. 14, no. 1, pp. 53-60, Sept. 2008.

[9] K. Aoki, T. Ichimori, M. Kanezashi, "Normal state optimal load allocation in distribution systems", IEEE Trans Power Deliv, vol. 3, no. 1, pp. 147-155, 1985.

[10] K. Prakash, A. Lallu, F.R. Islam and K. Mamun, "Review of Power System Distribution Network Architecture," in Computer Science and Engineering (APWC on CSE), 3rd Asia-Pacific World Congress, Nadi, 2016.

[11] F. R. Islam, K. Prakash, K. A. Mamun, A. Lallu, H. R. Pota Aromatic Network: A Novel Structure for Power Distribution System. IEEE Access. 2017 Oct 27.

[12] S. I. Wamoto, Y. Tamura, IEEE trans. On power apparatus \& systems, 1981.

[13] I. S. Bayram, G. Michailidis, M. Devetsikiotis, S. Bhattacharya, A. Chakrabortty, and F. Granelli, "Local energy storage sizing in plugin hybrid electric vehicle charging stations under blocking probability constraints," in Smart Grid Communications (SmartGridComm), 2011 IEEE International Conference on. IEEE, 2011, pp. 78-83.

[14] IEEE PES Distribution System Analysis Subcommittee's Distribution Test Feeder Working Group, URL: http://ewh.ieee.org/soc/pes/dsacom/testfeeders/index.html

[15] Y. Baghzouz, S. Ertem, "Shunt Capacitor Sizing for Radial Distribution Feeders with Distorted Substation Voltages", IEEE Trans. on Power Delivery, vol. 5, no. 2, pp. 650-65, April 1990.

[16] Chopade, Pravin, and Marwan Bikdash. "Minimizing cost and power loss by optimal placement of capacitor using ETAP." In System Theory (SSST), 2011 IEEE 43rd Southeastern Symposium on, pp. 24-29. IEEE, 2011.

[17] Al-Naseem, Osama A, and Ahmad Kh Adi. "Impact of power factor correction on the electrical distribution network of Kuwaita case study." Online J Power Energy Eng 1 (2003): 173-176.

[18] ETAP User Guide. Southern California : Operation Technology, Inc, 2015.

[19] Van Vliet, O., Brouwer, A. S., Kuramochi, T., van Den Broek, M., \& Faaij, A. (2011). Energy use, cost and CO 2 emissions of electric cars. Journal of Power Sources, 196(4), 2298-2310. 